\title{
Bioassay Studies of Silkworm Bombyx mori L. on Tree Mulberry Genotypes in Different Seasons
}

\author{
B. N. Ahalya*, Chikkalingaiah, Fatima Sadatulla and K. Murali \\ Department of Sericulture, UAS, GKVK, Bengaluru-65, India \\ *Corresponding author
}

\begin{abstract}
A B S T R A C T
Studies on different tree mulberry genotypes on rearing performance of silkworm (Bombyx mori L.) was carried out to identify the best performing genotypes based on the bioassay performance of silkworm cross breed PM x CSR2 during rainy, winter and summer seasons of 2018-19at the Department of Sericulture, University of Agricultural Sciences, GKVK, Bangalore. The present study comprised of six mulberry genotypes viz., MI-012, MI-79, MI-21, MI-139, MI-516, ME-05 and two check varieties V1 and M5. These mulberry genotypes as tree were allowed to grow crown height of 5 feet from the ground level and maintained as tree. The performance of tree mulberry genotypes varied significantly for different larval and cocoon characters in different seasons. Among the genotypesMI-012 performed better by recording highest mean cocoon parameters viz., cocoon weight $(1.67 \mathrm{~g})$, pupal weight $(1.39 \mathrm{~g})$, silk filament length $(769.70 \mathrm{~m})$, silk filament weight $(0.24 \mathrm{~g})$ and silk productivity $(3.24 \mathrm{cg} / \mathrm{day})$. On the other hand ME-05 recorded maximum cocoon shell weight $(0.38 \mathrm{~g})$, cocoon shell ratio $(17.57 \%)$ and effective rate of rearing $93.11 \%$. Whereas, the genotype MI-516 recorded significantly maximum fifth instar larval weight $26.58 \mathrm{~g}$ followed by MI-012 (26.41g).The genotype ME-79 recorded significantly maximum denier (2.79), followed by MI-012 (2.76) when compared to other genotypes. Based on the bioassay study of silkworm, MI-012 has found to be best performing genotype as tree mulberry with respect to different larval and cocoon parameters.
\end{abstract}

\section{Keywords}

Tree mulberry,

Bioassay,

Genotypes,

Silkworm

\section{Article Info}

Accepted:

17 August 2020

Available Online:

10 September 2020

\section{Introduction}

Mulberry foliage is the only food for the silkworm (Bombyx mori L.) and is grown under varied climatic conditions, ranging from temperate to tropical. Mulberry leaf is a major economic component in sericulture since the quality and quantity of leaf produced per unit area have a direct bearing on cocoon harvest (Datta, 2000). The most important use of mulberry globally is for the rearing of silkworm, which feeds exclusively on its leaves. To increase the silk production, there is a need to develop highly productive mulberry varieties and silkworm races and also silkworm races tolerant to adverse climatic conditions and diseases which can come mainly from the sericulture germplasm resources and also from the wild relatives of Bombyx species available in the natural 
habitats. According to Miyashitha (1986), several factors are known to contribute for successful cocoon crop production viz., mulberry leaf $(38.2 \%)$, climate $(37.0 \%)$, rearing techniques $(9.3 \%)$, silkworm breed $(4.2 \%)$ and other factors $(8.2 \%)$. In recent years, much emphasis has been given to produce superior quality of raw silk to compete in the international market. To achieve this goal, efforts are being made to increase the production of good quality mulberry leaves which directly influence on the quality and quantity of raw silk produced.

India is the second largest producer of silk and also the largest consumer of silk in the world. Currently it produces about 35,468 MT of raw silk of which 25,345 MT is being contributed by mulberry silk, during 2018-19. Karnataka is considered as pioneering state contributing about 65 per-cent with an area of 1 , 04,578ha under mulberry cultivation. (Annon, 2018-19).

Mulberry is perennial, deciduous, deep rooted, fast growing and high biomass producing tree. The quantity and quality of the silk is directly proportional to the quality of mulberry leaves fed to the silkworm larvae thereby positively affecting the overall cocoon production. The nutritional quality of mulberry leaves plays an important role in nutrition of silkworm and in turn cocoon. The mulberry leaves alone contribute 38.20 per cent for quality cocoon production. Keeping in view, as 50 per-cent of the area under mulberry is rain dependent for its moisture requirement, growing mulberry as a high bush/low tree helps the root system to develop more extensively and deeper into the soil. Problem of cultivation of large area of nonavailable areable land in hilly terrains of the country. Regular intercultivation can be reduced when compared to bush form, since the tree is perennial, root growth is deep hence it can be mitigating the long moisture stress condition with normal foliage yield. Wider spacing in tree mulberry helps to free movement of air and sunlight hence there is a less chance of pest and diseases in the crop, good quality leaf can be obtained. Mechanization of intercultural operation is also easy. There is no spoilage of the leaf during harvesting and intercultivation.

In general, mulberry can be cultivated in three forms viz., bush, low-cut and tree (Qader et al., 1991). The bush system requires sufficient irrigation and the low cut system of plantations should be raised only with assured irrigation levels. The leaf wastage will be more in case of bush mulberry (i.e., 20\% is discarded which is soiled at the bottom). In such situations the tree mulberry cultivation is the best method which has various advantages over the bush system of cultivation viz., mulberry can be grown even in water stress conditions without affecting yield, no wastage of leaf, quality cocoons can be ensured and intercrops can be grown which adds to the profit of the farmer (Hullunachegowda, 2016). In the present study, the effect of feeding of different leaves harvested from tree mulberry genotypes on bioassay studies of silkworm (Bombyx mori L.) has been undertaken.

\section{Materials and Methods}

Bioassay studies on tree mulberry genotypes in different seasons were carried out during the year 2018-2019 in the Department of Sericulture, University of Agricultural Sciences, GKVK, Bengaluru-65. The experimental material for the present study comprised of six elite mulberry genotypes viz., MI-012, MI-79, MI-21, MI-139, MI-516, ME-05 and two check varietiesV1 and M5.Two and half months old saplings were transferred to main field during 2015-16 only one sapling per pit was planted with a spacing of $5 \times 5$ feet with RCBD design in three 
replications. These mulberry genotypes as tree were allowed to grow tall with a crown height of 5 feet from the ground level side branches were removed.The experimental plot is maintained as per the recommended package of practices for rain-fed mulberry (Dandin and Giridar, 2010). The genotypes were evaluated on $60^{\text {th }}$ day after pruning for bioassay studies of silkwormduring rainy, winter and summer season.

Silkworm (Bombyx mori L.) crossbreed PM $\times$ CSR2 were reared by feeding the leaves of different tree mulberry genotypes individually during three seasons with three replications. The silkworm rearing house will be maintained as per the specifications of favorable environmental conditions of temperature, humidity and sunlight (Dandin and Giridhar, 2010).Prior to commencement of rearing, the rearing room with rearing stands were cleaned, washed thoroughly and properly disinfected with sanitech solution using a foot pump as adopted by Dandin et $a l$. , (2003). After spraying, the room was kept closed for 48 hours for effective disinfection. Later the doors and windows were kept open to allow the fresh air into the rearing room. The chawki worms were reared by feeding three times a day (7.00 am, 1.00 and $6.00 \mathrm{pm})$ with tender leaves in plastic trays. Whereas, late age worms were fed with harvesting entire leaf. Bed cleaning was done twice and thrice during II and III instar respectively and two times during IV instar (once after III moult and again before settling for IV moult) and daily once during fifth instar. During rearing optimum spacing was provided according to the age of worms i.e., after each bed cleaning. Lime powder and vijetha were dusted on silkworm before and after moulting (Dandin and Giridar, 2010). The mature larvae were picked up from the rearing bed and mounted on chandrike @ 50 worms per square feet for cocoon spinning. The cocoons were harvested on fifth day after mounting for assessment of different cocoon parameters. The experimental data were analysed statistically by using CRD design with three replications.

\section{Results and Discussion}

Being a monophagous and commercially exploited, silkworm, Bombyx mori L. solely feeds on mulberry (Morus alba L.). The ultimate goal of sericulture is the quality cocoon production which mainly depends on the quality of the mulberry leaf and the rearing practices. In the present study the bioassay performance of silkworms on different tree mulberry genotypes were assessed during different seasons. Among the six genotypes none of the genotypes performed better than the check varieties.

\section{Fifth instar larval weight (g)}

The fifth instar larval weight varied significantly when silkworms were fed with leaves harvested from tree mulberry genotypes. The genotype MI-516 recorded maximum mean fifth instar larval weight $26.58 \mathrm{~g}$. Whereas, the genotype MI-21 recorded least mean larval weight $(23.48 \mathrm{~g})$ compared to other tree mulberry genotypes. Among the different seasons the genotypes MI-012, MI-516 and ME-05 was recorded highest larval weight of $28.69 \mathrm{~g}, 25.42 \mathrm{~g}$ and $26.66 \mathrm{~g}$ respectively in all the seasons (Table 1). The present results are in line with the findings of earlier workers. Tewary et al., (2008) reported weight of ten mature larvae $31.50 \mathrm{~g}$ when silkworms were fed with leaves from tree mulberry. Whereas, Vanitha and Narayanaswamy, 2019, who reported the maximum larval weight $4.79 \pm$ $0.45 \mathrm{~g}$, when silkworms were reared on leaves harvested from tree mulberry. Similar results were also obtained by Sudhakar et al., (2018), who recorded highest larval weight of $17.3 \mathrm{~g}$ when silkworms were fed with leaves from tree mulberry. 


\section{Cocoon weight (g)}

The cocoon weight differed significantly when silkworms were fed with leaves harvested from different tree mulberry genotypes. The genotype MI-012 recorded highest mean cocoon weight $(1.67 \mathrm{~g})$. Whereas, the genotype MI-21 recorded least mean cocoon weight $(1.35 \mathrm{~g})$ when compared to other genotypes. Among the different seasons MI-012 recorded highest cocoon weight $(1.80$ and $1.60 \mathrm{~g})$ in both rainy and winter seasons. Whereas, the genotype ME-05 recorded highest cocoon weight $(1.62 \mathrm{~g})$ in summer season (Table 1). These results are line with the findings of earlier reports. Tewary et al., (2008) reported maximum cocoon weight $(1.56 \mathrm{~g})$ when silkworms were fed with tree mulberry leaves. Maribashetty et al., (1999) reported the cocoon weight in batches fed with tree mulberry leaves at different seed multiplication stages were 1.81 (P4), $1.82 \mathrm{~g}$ (P3) and $1.72 \mathrm{~g}$ (P2. Shakhawat et al., 2016, who reported highest single cocoon weight $1.28 \pm 0.04$ when silkworms were fed with tree mulberry leaves. Sudhakar et al., 2018, who recorded highest ten cocoon weight of $17.3 \mathrm{~g}$ when leaves harvested from tree mulberry. The present results are conformity with the findings of Vanitha and Narayanaswamy, 2019, they have recorded the maximum cocoon weight $1.74 \pm 0.03 \mathrm{~g}$ when silkworms were grown on leaves harvested from tree mulberry.

\section{Single cocoon shell weight (g)}

The single cocoon shell weight varied significantly when silkworms were reared on different tree mulberry genotypes. The genotype ME-05 recorded highest cocoon shell weight $(0.29 \mathrm{~g})$. Whereas, the genotype MI-21 recorded least cocoon shell weight $(0.22 \mathrm{~g})$ when compared to other genotypes. Among the different seasons the genotype ME-05 recorded highest single cocoon shell weight $(0.38 \mathrm{~g}, 0.27 \mathrm{~g}$ and $0.29 \mathrm{~g})$ in all the seasons (Table 2). These results are in line with the findings of earlier workers. Maribashetty et al., (1999) reported, highest cocoon shell weight at different seed multiplication stages as $0.37 \mathrm{~g}(\mathrm{P} 4), 0.36 \mathrm{~g}$ (P3) and $0.35 \quad \mathrm{~g}$ (P2). Vanitha and Narayanaswamy, 2019, recorded maximum shell weight $0.39 \pm 0.01 \mathrm{~g}$ when silkworms were reared on leaves from tree mulberry.

\section{Pupal weight (g)}

The genotype MI-012 recorded highest mean pupal weight $(1.39 \mathrm{~g})$ when silkworms were reared on leaves harvested from different tree mulberry genotypes. Whereas the genotype MI-21 recorded least mean pupal weight $(1.15 \mathrm{~g})$ compared to other mulberry genotypes. Among the different seasons the genotype MI012 registered highest pupal weight $(1.45 \mathrm{~g}$ and $1.34 \mathrm{~g})$ in both rainy and winter season. Whereas, the genotype ME-05 yielded highest pupal weight $(1.35 \mathrm{~g})$ in summer season (Table 2). The present results are on par with the results of earlier workers. Narayanaswamy et al., (2003) who reported highest pupal weight $(1.64 \mathrm{~g})$ when silkworms were fed with leaves from tree mulberry. Vanitha and Narayanaswamy, 2019, also recorded the maximum pupal weight $1.36 \pm$ $0.02 \mathrm{~g}$ when silkworms were reared on leaves harvested from tree mulberry.

\section{Cocoon shell ratio}

The cocoon shell ratio varied significantly when silkworms were reared on leaves harvested from different tree mulberry genotypes. The genotype ME-05 recorded highest mean cocoon shell ratio $(17.57 \%)$. Whereas, the genotype MI-21 recorded least mean cocoon shell ratio (14.81\%). Among the different seasons the genotype MI-516 recorded maximum cocoon shell ratio $(17.61 \%$ and $17.46 \%)$ in both winter and 
summer season respectively. Whereas, the genotype ME-05 recorded maximum cocoon shell ratio (18.55\%) in rainy season (Table 3 ). Tewary et al., (2008) recorded the highest shell ratio 17.00 per cent when silkworms grown on leaves harvested from tree mulberry. Shakhawat et al., (2016), also recorded highest shell ratio of $12.30 \pm 0.03 \%$.
Sudhakar et al., (2018), who also recorded highest single cocoon shell ratio of 21 per cent. Vanitha and Narayanaswamy (2019), also opined that maximum shell ratio $20.94 \pm$ $0.82 \%$ was recorded when silkworms were grown on leaves harvested from tree mulberry.

Table.1 Performance of tree mulberry genotypes for larva land cocoon weight of PM $\times$ CSR2 in different seasons

\begin{tabular}{|l|l|l|l|l|l|l|l|r|r|}
\hline \multirow{2}{*}{$\begin{array}{l}\text { SI. } \\
\text { No }\end{array}$} & \multirow{2}{*}{ Genotypes } & \multicolumn{4}{|c|}{ 10 Larval weight (g) } & \multicolumn{4}{c|}{ Cocoon weight (g) } \\
\cline { 3 - 11 } & & \multicolumn{4}{|c|}{ Season } \\
\cline { 3 - 10 } & & Rainy & Summer & Winter & Mean & Rainy & Summer & Winter & Mean \\
\hline $\mathbf{1}$ & MI-012 & 28.69 & 25.51 & 25.03 & 26.41 & 1.80 & 1.61 & 1.60 & 1.67 \\
\hline $\mathbf{2}$ & MI-79 & 27.80 & 25.01 & 22.47 & 25.10 & 1.67 & 1.49 & 1.37 & 1.51 \\
\hline $\mathbf{3}$ & MI-21 & 26.97 & 23.18 & 20.30 & 23.48 & 1.44 & 1.31 & 1.30 & 1.35 \\
\hline $\mathbf{4}$ & MI-139 & 28.36 & 23.91 & 23.03 & 25.10 & 1.63 & 1.48 & 1.42 & 1.51 \\
\hline $\mathbf{5}$ & MI-516 & 27.75 & 26.56 & 25.42 & 26.58 & 1.66 & 1.53 & 1.53 & 1.57 \\
\hline $\mathbf{6}$ & ME-05 & 28.12 & 26.66 & 23.46 & 26.08 & 1.77 & 1.62 & 1.55 & 1.65 \\
\hline $\mathbf{7}$ & M5 & 29.65 & 27.01 & 26.65 & 27.77 & 1.76 & 1.68 & 1.62 & 1.69 \\
\hline $\mathbf{8}$ & V1 & 30.00 & 28.19 & 27.67 & 28.62 & 1.92 & 1.75 & 1.72 & 1.80 \\
\hline & C.D. 5\% & 1.884 & 1.272 & 1.829 & 0.912 & 0.293 & 0.127 & 0.054 & 1.593 \\
\hline & SE m \pm & 0.638 & 0.424 & 0.610 & 0.559 & 0.098 & 0.042 & 0.018 & 0.061 \\
\hline & C.V. & 3.889 & 2.854 & 4.356 & 3.67 & 9.928 & 4.698 & 2.075 & 6.56 \\
\hline
\end{tabular}

Table.2 Performance of tree mulberry genotypes for shell weight and pupal weight of $\mathrm{PM} \times \mathrm{CSR} 2$ in different seasons

\begin{tabular}{|l|l|c|c|c|c|c|c|c|c|}
\hline \multirow{2}{*}{$\begin{array}{l}\text { Sl. } \\
\text { No }\end{array}$} & Genotypes & \multicolumn{4}{|c|}{ Shell weight(g) } & \multicolumn{4}{c|}{ Pupal weight (g) } \\
\cline { 3 - 11 } & & \multicolumn{4}{|c|}{ Season } & \multicolumn{4}{c|}{ Season } \\
\cline { 3 - 10 } & & Rainy & Summer & Winter & Mean & Rainy & Summer & Winter & Mean \\
\hline $\mathbf{1}$ & MI-012 & 0.31 & 0.28 & 0.25 & 0.28 & 1.49 & 1.33 & 1.34 & 1.39 \\
\hline $\mathbf{2}$ & MI-79 & 0.24 & 0.22 & 0.20 & 0.22 & 1.42 & 1.27 & 1.17 & 1.29 \\
\hline $\mathbf{3}$ & MI-21 & 0.22 & 0.19 & 0.19 & 0.20 & 1.22 & 1.11 & 1.12 & 1.15 \\
\hline $\mathbf{4}$ & MI-139 & 0.29 & 0.25 & 0.24 & 0.26 & 1.35 & 1.22 & 1.18 & 1.25 \\
\hline $\mathbf{5}$ & MI-516 & 0.29 & 0.27 & 0.27 & 0.28 & 1.37 & 1.26 & 1.26 & 1.30 \\
\hline $\mathbf{6}$ & ME-05 & 0.32 & 0.29 & 0.27 & 0.29 & 1.45 & 1.35 & 1.28 & 1.36 \\
\hline $\mathbf{7}$ & M5 & 0.32 & 0.30 & 0.29 & 0.30 & 1.45 & 1.39 & 1.33 & 1.39 \\
\hline $\mathbf{8}$ & V1 & 0.35 & 0.31 & 0.30 & 0.32 & 1.57 & 1.44 & 1.42 & 1.48 \\
\hline & C.D. 5\% & 0.029 & 0.026 & 0.020 & 0.013 & 0.305 & 0.138 & 0.060 & 0.104 \\
\hline & SE m \pm & 0.010 & 0.009 & 0.007 & 0.008 & 0.102 & 0.046 & 0.020 & 0.064 \\
\hline & C.V. & 5.729 & 5.687 & 4.508 & 5.00 & 12.44 & 6.154 & 2.758 & 8.240 \\
\hline
\end{tabular}


Table.3 Performance of tree mulberry genotypes for larval and cocoon parameters of PM $\times$ CSR2 in different seasons

\begin{tabular}{|l|l|l|l|l|l|l|l|c|c|}
\hline \multirow{2}{*}{ SI. No } & \multirow{2}{*}{ Genotypes } & \multicolumn{4}{|c|}{ Cocoon shell ratio (\%) } & \multicolumn{4}{c|}{ Effective rate of rearing (\%) } \\
\cline { 3 - 11 } & & \multicolumn{3}{|c|}{ Season } & \multicolumn{4}{c|}{ Season } \\
\cline { 3 - 11 } & & Rainy & Summer & Winter & Mean & Rainy & Summer & Winter & Mean \\
\hline $\mathbf{1}$ & MI-012 & 17.32 & 17.45 & 15.87 & 16.88 & 93.33 & 92.00 & 93.33 & 92.89 \\
\hline $\mathbf{2}$ & MI-79 & 15.40 & 14.58 & 14.63 & 14.87 & 94.00 & 93.33 & 89.33 & 92.22 \\
\hline $\mathbf{3}$ & MI-21 & 15.30 & 14.81 & 14.33 & 14.81 & 93.33 & 92.00 & 88.00 & 91.11 \\
\hline $\mathbf{4}$ & MI-139 & 17.60 & 17.16 & 17.14 & 17.30 & 94.00 & 91.33 & 90.67 & 92.00 \\
\hline $\mathbf{5}$ & MI-516 & 17.51 & 17.46 & 17.61 & 17.53 & 94.00 & 90.67 & 89.33 & 91.33 \\
\hline $\mathbf{6}$ & ME-05 & 18.05 & 17.06 & 17.60 & 17.57 & 94.00 & 94.00 & 91.33 & 93.11 \\
\hline $\mathbf{7}$ & M5 & 17.96 & 17.66 & 17.92 & 17.85 & 94.67 & 93.33 & 92.67 & 93.56 \\
\hline $\mathbf{8}$ & V1 & 18.26 & 17.97 & 17.41 & 17.88 & 96.67 & 94.67 & 93.33 & 94.89 \\
\hline & C.D. 5\% & 4.033 & 2.231 & 1.545 & 1.47 & 4.469 & 3.805 & 3.739 & 2.19 \\
\hline & SE m \pm & 1.345 & 0.744 & 0.515 & 0.902 & 1.491 & 1.269 & 1.247 & 1.342 \\
\hline & C.V. & 13.567 & 7.688 & 5.389 & 9.22 & 2.740 & 2.372 & 2.374 & 2.49 \\
\hline
\end{tabular}

Table.4 Performance of tree mulberry genotypes for filament length and filament weight of $\mathrm{PM} \times \mathrm{CSR} 2$ in different seasons

\begin{tabular}{|l|c|c|c|c|c|c|c|c|c|}
\hline \multirow{2}{*}{$\begin{array}{l}\text { SI. } \\
\text { No }\end{array}$} & \multirow{2}{*}{ Genotypes } & \multicolumn{3}{|c|}{ Single cocoon filament length $\mathbf{( c m )}$} & \multicolumn{3}{c|}{ Single cocoon filament wt.(g) } \\
\cline { 3 - 12 } & & \multicolumn{3}{|c|}{ Season } & \multicolumn{4}{c|}{ Season } \\
\hline $\mathbf{1}$ & Rainy & Summer & Winter & Mean & Rainy & Summer & Winter & Mean \\
\hline $\mathbf{2}$ & MI-012 & 799.24 & 770.37 & 769.70 & 779.77 & 0.25 & 0.24 & 0.23 & 0.24 \\
\hline $\mathbf{3}$ & MI-79 & 750.42 & 748.23 & 747.09 & 748.58 & 0.24 & 0.23 & 0.22 & 0.23 \\
\hline $\mathbf{4}$ & MI-21 & 721.40 & 720.34 & 719.40 & 720.38 & 0.22 & 0.21 & 0.21 & 0.21 \\
\hline $\mathbf{5}$ & MI-139 & 725.73 & 722.37 & 720.46 & 722.85 & 0.23 & 0.22 & 0.21 & 0.22 \\
\hline $\mathbf{6}$ & MI-516 & 758.62 & 742.51 & 734.62 & 745.25 & 0.240 & 0.22 & 0.22 & 0.23 \\
\hline $\mathbf{7}$ & ME-05 & 759.06 & 755.74 & 752.73 & 755.84 & 0.24 & 0.24 & 0.22 & 0.23 \\
\hline $\mathbf{8}$ & M5 & 805.93 & 795.90 & 790.54 & 797.46 & 0.26 & 0.25 & 0.24 & 0.25 \\
\hline & V1 & 816.29 & 800.45 & 799.36 & 805.37 & 0.27 & 0.26 & 0.25 & 0.26 \\
\hline & C.D. 5\% & 6.119 & 8.704 & 5.988 & 3.86 & 0.017 & 0.020 & 0.015 & 0.01 \\
\hline & SE m \pm & 2.041 & 2.903 & 1.997 & 2.369 & 0.006 & 0.007 & 0.005 & 0.067 \\
\hline
\end{tabular}


Table.5 Performance of tree mulberry genotypes for filament length and silk productivity of $\mathrm{PM} \times \mathrm{CSR} 2$ in different seasons

\begin{tabular}{|l|l|l|c|c|c|c|c|c|r|}
\hline \multirow{2}{*}{$\begin{array}{l}\text { Sl. } \\
\text { No }\end{array}$} & Genotyp & \multicolumn{4}{|c|}{ Filament denier } & \multicolumn{4}{c|}{ Silk productivity (cg/day) } \\
\hline & & \multicolumn{4}{|c|}{ Season } & \multicolumn{4}{c|}{ Season } \\
\hline $\mathbf{1}$ & MI-012 & 2.82 & 2.77 & 2.69 & 2.76 & 3.58 & 3.35 & 2.78 & 3.24 \\
\hline $\mathbf{2}$ & MI-79 & 2.92 & 2.76 & 2.69 & 2.79 & 2.79 & 2.60 & 2.24 & 2.54 \\
\hline $\mathbf{3}$ & MI-21 & 2.74 & 2.67 & 2.63 & 2.68 & 2.39 & 2.20 & 2.04 & 2.21 \\
\hline $\mathbf{4}$ & MI-139 & 2.85 & 2.78 & 2.62 & 2.75 & 3.19 & 2.87 & 2.71 & 2.92 \\
\hline $\mathbf{5}$ & MI-516 & 2.81 & 2.71 & 2.74 & 2.75 & 3.40 & 3.19 & 2.88 & 3.16 \\
\hline $\mathbf{6}$ & ME-05 & 2.85 & 2.82 & 2.59 & 2.75 & 3.03 & 3.55 & 3.03 & 3.20 \\
\hline $\mathbf{7}$ & M5 & 2.90 & 2.81 & 2.73 & 2.81 & 3.45 & 3.80 & 3.22 & 3.49 \\
\hline $\mathbf{8}$ & V1 & 2.94 & 2.89 & 2.78 & 2.87 & 3.68 & 3.85 & 3.36 & 3.63 \\
\hline & C.D. 5\% & 0.199 & 0.234 & 0.183 & 0.11 & 0.413 & 0.377 & 0.248 & 0.210 \\
\hline & SE m \pm & 0.067 & 0.078 & 0.061 & 0.071 & 0.138 & 0.126 & 0.083 & 0.070 \\
\hline & C.V. & 4.039 & 4.880 & 3.948 & 4.40 & 7.488 & 6.861 & 5.139 & 3.976 \\
\hline
\end{tabular}

\section{Effective rate of rearing}

The genotype ME-05 recorded highest percentage of mean effective rate of rearing $(93.11 \%)$ when silkworms were reared on leaves harvested from different tree mulberry genotypes. Whereas, the genotype MI-21 recorded least mean effective rate of rearing (91.11\%) compared to others. Among the different seasons the genotypes viz., ME-05, MI-79, MI-139 and MI-516 recorded maximum effective rate of rearing $94.00 \%$ when silkworms were reared on rainy season. Whereas, MI-012 recorded highest effective rate of rearing (93.33) in winter season on the other hand the genotype ME-05 recorded highest effective rate of rearing (94.00\%) during summer season (Table 3). Sudhakar et al., 2018, opined that highest effective rate of rearing (97.4\%) was recorded when silkworms were reared on leaves harvested from tree mulberry.

\section{Single cocoon filament length}

The genotype MI-012 recorded significantly longer mean silk filament length $(779.77 \mathrm{~m})$.
Whereas, the genotype MI-21 recorded lesser mean filament length $(719.40 \mathrm{~m})$ when compared to other genotypes.

Among the different seasons the genotype MI-012 recorded highest filament length $(799.24 \mathrm{~m}, 769.70 \mathrm{~m}$ and $770.35 \mathrm{~m})$ in all the seasons (Table 4). These results are in conformity with the findings of Shakhawat $e t$ al., (2018), who reported highest cocoon filament length $384.67 \pm 12.34$.

\section{Single cocoon filament weight}

The genotype MI-012 recorded significantly maximum mean silk filament weight $(0.24 \mathrm{~g})$ when silkworms were fed with leaves harvested from tree mulberry genotypes.

Whereas, the genotype MI-21 recorded lesser mean filament weight $(0.21 \mathrm{~g})$ compared to other genotypes. Among the different seasons the genotype MI-012 recorded highest filament weight $(0.25 \mathrm{~g}, 0.23 \mathrm{~g}$ and $0.24 \mathrm{~g})$ rainy, winter and summer respectively (Table 4). 


\section{Filament denier}

Significant differences were observed with respect to filament denier in different genotypes. The genotype MI-79 recorded significantly maximum mean filament denier (2.79) when compared to other genotypes. Whereas, the genotype MI-21 recorded minimum mean filament denier (2.68). Among the different seasons the genotype ME-05 recorded maximum filament denier (2.85 and 2.82) in both rainy and summer respectively and the genotype MI-516 recorded significantly maximum denier (2.74) during summer season compared to other genotypes (Table 5). Shakhawat et al., 2018, opined that the highest denier was recorded when silkworms were reared leaves harvested from tree mulberry $3.17 \pm 0.05$.

\section{Silk productivity (cg/day)}

The Silk productivity varied significantly when silkworms were reared on leaves harvested from different tree mulberry genotypes. The genotype MI-012 recorded highest mean silk productivity $(3.24 \mathrm{cg} /$ day) compared to other genotypes. Whereas, the genotype MI-21recorded least mean silk productivity $(2.21 \mathrm{cg} /$ day $)$. Among the different seasons the genotype ME-05 recorded maximum denier $(3.03 \mathrm{cg} /$ day and $3.55 \mathrm{cg} /$ day) in winter and summer respectively. Whereas, the genotype MI-012 recorded maximum silk productivity (3.58 cg/day) in rainy season (Table 5).

Study revealed that, the performance of tree mulberry genotypes during different seasons on bioassay studies of silkworms indicated that, none of the genotypes performed better than the check varieties. However, the genotype MI-012 performed superior in respect of different traits viz., cocoon weight, pupal weight, filament weight, filament length and silk productivity followed by the genotype ME-05. On the other hand genotype ME-05performed superior in respect of different traits viz., shell weight, shell ratio and effective rate of rearing. By considering different larval and cocoon parameters in different seasons the performance of silkworm was better in rainy season followed by summer and winter season.

\section{References}

Anonymous, 2018-19, Annual Report, Central Silk Board, Bangalore, P. 95114.

Anonymous, 2015, Annual Report, Central Silk Board, Bangalore, P. 95-114.

Dandin, S. B., Jayswal, J. and Giridhar, K., 2003, Hand Book of Sericulture Technologies, CSB publications, P.230.

Dandin, S. B. and GiridhAR, K., 2010, Hand book of sericulture technologies, CSB publications, P.13.

Datta, R. K., 2000, Mulberry cultivation and utilization in India. FAO Conference on Mulberry and Animal Production, pp.124.

Hullunachegowda, K. R., 2016, Organic Tree Mulberry Cultivation under Dryland Situation,Technical Brochure, Published by MicrobialAgrotechnology Private Limited, Bengaluru, P. 6.

Tewary, P.K., Singh, M.K., Sinha, U.P.S. and Bajpai, 2008, Mulberry as small tree - a new approach for sustainable sericulture in Jharkhand. Indian Silk, 46 (7): 10-11.

Maribashetty, V. G., Raghuraman, R., Venkatesh, H. and Puttaswamy, S., 1999, Comparative nutritive value of bush and tree mulberry leaves in bivoltine seed rearing. Sericologia, 39 (1): 67-72.

Miyashitha, V., 1986, A Report on Mulberry and Training Methods Suitable to Bivoltine Rearing in Karnataka. Central Silk Board, Bengaluru. p. 1-7. 
Narayanaswamy, K. C., Manjunath Gowda and Shivakumar, H. R., 2003, Impact of feeding mulberry leaves from tree and bush plantations on grainage parameters of a fewbivoltine silkworm breeds,National Seminar on Silkworm Seed Production, SSTL, Bengaluru. pp. 35-37.

Qader, M. A., Sarker A. A. and S.U., Ahmed, 1991. Comparative study on the nutritive value of bush, low-cut and tree mulberry leaves at different maturity stages. Sericologia. 31 (3): 429-435.

Vanitha, C. and Narayanaswamy, K. C., 2019, Performance of Silkworm on Tree Mulberry, Morus alba L., International Journal of Current Microbiology and
Applied Sciences, 8(4): 2020-2025.

Sudhakar, P., Hanumantharayappa, S. K., Sudhakar Rao. P., Jalaja S Kumar and Sivaprasad, V., 2018, Tree mulberry sustainable and economically viable Sericultural farming for southern tropical zones, International Journal of Applied and Pure Science and Agriculture, p.no- 2394-823.

Shakhawat Hossain, Saiful Islam and Moinul Haque, 2016, Influence of different cultivation forms of mulberry variety BM-3 (Morus alba) on leaf nutrition, yield and economic traits of silkworm, Elixir Applied. Chemistry. 95, 4116941172.

\section{How to cite this article:}

Ahalya, B. N., Chikkalingaiah, Fatima Sadatulla and Murali, K. 2020. Bioassay Studies of Silkworm Bombyx mori L. on Tree Mulberry Genotypes in Different Seasons. Int.J.Curr.Microbiol.App.Sci. 9(09): 2275-2283. doi: https://doi.org/10.20546/ijcmas.2020.909.283 